\title{
A New Mobile Learning Model in the Context of Smart Classroom Environment:
}

\author{
A Holistic Approach \\ https://doi.org/10.3991/ijim.v11i3.6186 \\ Ahmed Al-Hunaiyyan \\ Public Authority of Applied Education and Training, Kuwait \\ Hunaiyyan@ hotmail.com \\ Salah Al-Sharhan \\ Gulf University for Science, and Technology, Kuwait \\ alsharhans@gust.edu.kw \\ Rana Alhajri \\ Public Authority of Applied Education and Training, Kuwait \\ Rana_alhajri@yahoo.com
}

\begin{abstract}
This paper proposes a comprehensive mobile learning model in the context of smart classroom environment as a part of a holistic approach to implement an efficient Technology Enhanced Learning (TEL) environment. In this proposed model, the components of the mobile learning as being essential parts of a smart classroom and systematically integrate the mobile features with teaching and learning environment. However, there are many challenges to generalize about this type of learning in any educational system. One of the major causes of these challenges is the lack of an integrated model in a holistic approach to smart classroom and TEL environment. Another critical challenge is not adopting an efficient m-learning inside the smart classrooms. In addition, incorporating many pedagogical and technological elements becomes a new dimension of complexity. The new model is introduced not only to implement a holistic m-learning approach capable of overcoming these challenges, but also to assist the schools and the stakeholders responsible for the national e-learning initiatives.
\end{abstract}

Keywords-Distance education, e-learning, Interactive learning environments, m-learning, Modeling, Smart classrooms.

\section{Introduction}

The main objective of implementing the Technology Enhanced Learning (TEL) is to provide an interactive learning environment based on utilizing the ICT tools. A wide range of collaboration tools, technologies, internet, and computer applications are utilized in the learning process of this environment [1]. Accordingly, conventional 
classrooms are drastically changed into rich technology-based classrooms, in other words smart classrooms. Students/learners can access the learning resources anytime, anywhere as the e-learning system provides the tools necessary for monitoring and tracking learners' performance. The core idea underlying the smart classrooms is to transform the educational system using a holistic approach to the TEL with an emphasis on students. This kind of education and knowledge are granted to everyone, anytime and anywhere. The vision of developing the smart classrooms is to utilize vital components required for taking advantage of technology in order to improve the educational system and the delivery means [2].

The cornerstone of the integrated e-learning framework is the transformative strategy of the smart classrooms. It focuses on connecting the digital generation, improving the individualized learning opportunities, sparking the innovation of learning, enhancing the teachers' digital pedagogy and achieving the best possible outputs of schools as an ICT investment [3, 4]. It's above all about re-designing schools' structure according to students' learning needs and achieving the transition from the traditional learning practices to new innovative ones that are relying on digital working environment. Such environment is meaningful, engaging and connected. Mobile learning plays a key role in this environment to achieve the expected objectives for developing smart classroom environment. Seyed Ebrahim et al. (2014) stated that mlearning is considered as the latest introduced type of learning where new learning strategies provided through mobile devices and applications [5]. Berking et al. (2013) believed that the mobile's unique capabilities including connectivity, portability, GPS, and cameras those have great potentials to enrich the teaching and learning experience [6].

The global technology revolution has manifested in transiting from desktop computing to widespread use of mobile technology. This technology offered opportunities for delivering new and interesting methods of learning whether inside or outside the classroom. The research supported the effectiveness of mobile technology. Besides, the literature indicated that m-learning has offered considerable benefits by building and supporting the creative, collaborative, interactive abilities and capacities inside the learning environments. Several authors have referred to the mobile learning capacity to enhance the collaborative learning [7]. Furthermore, some important benefits of mobile learning are allowing data and information collection, enhancing \& building knowledge and providing the necessary support by integrating work activities and students' experiences in learning [8,9].

In this paper, we propose a new m-learning model in the context of smart classrooms environment to effectively adapt the mobile technologies in the national educational systems. The significance of this work lies in having an efficient integration of mobile technologies in a smart classroom environment. Furthermore, the new model provides a foundation to successfully implement $21^{\text {st }}$ century learning capabilities [10], in Kuwait. It is noted that there is a lack of m-learning models and the frameworks are grounded in empirical research conducted in developing countries' contexts [11]. In addition, Traxler concluded that research on m-learning in developing countries should be valued to understand the challenges related to its unique cultures, infrastructure, and learning environment [12].The proposed model contributes in filling 
the gap through providing an efficient model for m-learning implementation in the region. The model is based on a holistic approach as well as on the lessons learned from the implementation of Kuwait e-learning project that was initiated by the Kuwait national e-learning strategy $[13,14]$.

What differentiates this proposed model compared to other models is presented in section II. It is explicitly integrating all the essential components and factors on the strategic, tactical and operational levels as explained in section V. These factors span all the influential elements such as technical, pedagogical, economical and human factors. The integration of these different dimensions and factors forms the base of the holistic mobile learning approach. Furthermore, the design of the proposed model was motivated by the study of other existing models and frameworks in the developed countries as reviewed in section II. Based on the revision of these models and frameworks, and the lessons learned from the Kuwait national e-learning strategy [14], many features and components have been identified and added to the proposed model in order to appropriately satisfy the specific situation in Kuwait and the entire region.

The rest of this paper is organized as: Section II discusses related studies, while Section III introduces new definition of m-learning in contest with TEL. It emphasizes on controlled learning environment. Smart classroom environment is introduced in section IV. Section V presents an integrated model for efficient m-learning inside smart classroom environment. In addition, it considers several successful factors related to educational systems and society. Section VI discusses challenges confronted to implement the proposed m-leaning new model. Section VII presents a case study and this paper concludes with section VIII and suggested future recommendations.

\section{Related Studies}

Researchers and academics are currently exploring the capabilities of the mobile technologies to support the learning process by proposing models and frameworks of implementing m-learning projects. Successful implementation of mobile learning systems requires an understanding of the impact of the technology on education and on current teaching and learning practices to identify the critical success factors, those need to be highlighted in the mobile learning strategy. New mobile learning models are emerging as new research findings in the area have become available to address the concerns of the stockholders and the challenges confronted by technology. These models and frameworks are valuable for better integration of technology and pedagogy as well as identifying the critical success factors that help a successful implementation.

An example of mobile technologies is the Smartphone as its sales is estimated to reach $88 \%$ of global mobile phone sales by 2018 [15]. The mobile technologies have significant interconnected features including portability, connectivity, and strong computing capabilities [16]. This allows mobile technologies to create great opportunities for flexible and ubiquitous learning [17]. Mobile learning models and frameworks, which have evolved from models that emphasized on technical issues and platform design of models and frameworks that focus on pedagogical issues, design, 
and the creation of online learning communities. Hsu et al. (2014) listed ten areas of research of mobile learning that should receive more attention and to be given higher priority in the next five years. They indicated that while there are increasing models and frameworks in mobile learning, more research effort is needed to provide guidance and to help identify gaps in the existing literature and provide future research directions in mobile learning [18].

The research conducted by Hus and Ching (2015), provided a comprehensive literature review and a synthesis of mobile learning models and frameworks. They divided the models and frameworks into five categories: 1) pedagogies and learning environment design; 2) platform/system design; 3) technology acceptance; 4) evaluation and 5) psychological construct. They stated that this work can help in evaluating, designing, and developing environments for meaningful mobile learning experiences [19].

Regarding m-learning evaluation, Alrasheedi (2015) developed a framework based on the well-known Capability Maturity Model (CMM) to evaluate the maturity of mobile learning projects. His objective was to first identify, classify and then group the key factors that affect m-learning adoption, and eventually use this as a theoretical basis for proposing a maturity model for m-learning [20]. In addition, Sarrab et al. (2016) proposed a model for evaluating the quality of mobile learning applications. They proposed a model able to capture m-learning non-functional requirements from social, cultural, pedagogical, business and economical dimensions [21]. Furthermore, Vavoula and Sharples (2009) proposed a framework to address six types of challenges when evaluating the mobile learning by using a three-level framework consisting of usability, learning experience, and integration within existing educational and organizational contexts. They stressed that a systematic examination of each level should be concluded at the end of each phase of any mobile learning project that is- design, development, and deployment [22].

Koole's (2009) Framework for the Rational Analysis of Mobile Education (FRAME) provided a practical checklist to assist educators to consider the foundational components and intersections of components of mobile learning when designing m-learning curricula. The Framework was built based on the three respective fundamental components of the mobile learning: device, learner, and social. Koole indicated that the intersection of these aspects allows designers and educators to consider the implications of involving any two of these aspects when designing mobile learning [23]. In addition, Peng et al. (2009) proposed a conceptual framework of ubiquitous knowledge construction. They discussed the issues of ubiquitous learning that include the learner, m-learning tools, and pedagogical methods which need to be addressed to achieve and scale up ubiquitous knowledge construction for mobile learning [24]. Furthermore, Park (2011) introduced a pedagogical framework that categorized mobile learning into four types. The goal of his framework was to help instructional designers to consider the extent of psychological separation between the learner and the instructor. Moreover, to allow academics and institutions to plan for the best method of learning and teaching experiences that may work well in their context [25].

Regarding technology acceptance, Huang et al. (2007) developed a general structural model. The model aims at verifying whether their extended Technology Ac- 
ceptance Model (TAM) could be used to predict mobile learning acceptance at a higher education level. The contribution of this model lies in its focus on learning in the mobile context, and its learners' acceptance of the mobile technologies as tools for learning [26]. Similarly, Park et al. (2012) conducted a statistical analysis to develop a general structural model. The data analysis concluded that the use of TAM helped to explain and to predict learners' acceptance the mobile learning at the university level. They identified several external factors that have direct or indirect effects on learners' behavioral intention of using mobile learning [27].

\section{M-learning: A New Definition in the TEL Context}

Mobile learning has been defined by different researchers. Some definitions are more into technical approach, while other definitions focus on pedagogy, educational aspects, and m-learning process. Traxler (2007) defined m-learning, as "an educational interaction delivered through mobile technology and accessed by learners from any location" [28]. Kinash et al. (2012) described m-learning as the use of mobile devices with an internet connection for educational setting [29]. The m-learning technology includes hardware such as: mobile phones, handheld PCs, tablets, as well as other mobile devices that can run mobile applications and includes software. There are mobile applications, those are designed specifically for learning purposes. Other applications and device capabilities such as sensors, cameras, location and maps, social media, web searching, augmented and virtual reality can be adapted for educational purposes and believed to present the potential to foster learning and engagement inside and outside the classroom [30].

The authors of this paper define m-learning in the context of a holistic approach of TEL as follows: m-learning is a learning strategy that provides students with the 21st century learning capabilities in order to enable them to utilize a wide range of the portable computing devices. These devices are connected via the smart classroom network or the Internet to smart components or online interactive educational content and learning resources. It means to be connected with a learning environment that is controlled by the teacher (instructor) using the Learning Management System (LMS) or tools of Social Online Learning (SOL) that achieve a collaborative, interactive and innovative learning environment.

We emphasize on our definition of m-learning as "control" as instructor is controlling the learning environment. On the other hand, m-learning was argued to be informal and made learning more casual [31]; caused frequent interruptions [32]; distracted the traditional learning environments [33]. Kadirire (2009) also observed that, in a mobile learning environment, there was less control over students which lead to losing some educational gains [32]. Understanding these issues, we agree to what have been addressed by [34] that. When conducting a course in a formal education setting, it is essential that the instructor has control over the learning environment and learning activities such as course announcements, assignments, assessment, and feedback. We can also benefit from some tools such as social network services where instructors can direct and help students to create and share their information with the instructor 
and other students. Although this allows more freedom on students' activities, but it is still going under the control definition. It means, instructors can use various assessment tools with the help of learning management systems capabilities that manage various mobile learning activities.

Perthe definition mentioned above, the m-learning possesses the following features:

- Portable devices

- 21 st century learning competencies

- Accessibility through connectivity Medium (Internet or Network)

- Smart classrooms components (smart interactive board, Audio/video components, class management system, etc.)

- Interactivity and Collaboration

- Interactive educational content

- Controlled collaborative learning environment (closed loop)

\section{Smart Classrooms}

Smart classrooms aim at offering distinguished educational environment which can enhance the collaborative learning environment and providing diverse knowledge sources through many interactive tools. In literature, smart classroom concept has evolved from broader concept that was the distance education system which utilized Internet as a medium in order to transform a conventional classroom into an intelligent space, equipped with several hardware and software components [35].

Al-Sharhan, (2016) introduced a holistic model and approach of the smart classroom environment in context with TEL [36]. He emphasized on that smart classrooms concept should not be associated with a conventional classroom, equipped with certain education technologies as it was in early days- such as projectors and overheads. Smart classrooms as described by [37], are technology enhanced classrooms that foster opportunities of teaching and learning by integrating the learning with technological tools. These tools are: computers, classroom management software with assistive listening devices, networking, and audio/visual capabilities. These classrooms contribute to and support the campus virtual learning spaces in terms of design, and planning. In addition to the virtual learning space created by smart classroom model, the new environment is based on different levels of interactivity and that exactly means more benefits to instructors as well as students. They will have educational technology, teaching/learning practice and active learning.

A smart classroom consists of several components to form an interactive and interesting learning environment to enrich the teaching methods, develop students' skills, raise their academic level, and to allow their further participation in the learning process. These components will add the dimensions of the real 'smartness' from the perspective of educational technology and innovation and pedagogical change management. Smart classroom's components interact with the other components of e-learning system in order to form a unique learning environment. This will contribute in effec- 
tively moving towards 21 st century education. In view of that, smart classroom's components are:

- Interactive smart whiteboard

- Classroom and Multimedia Control Center

- Computers and Mobile computing that serve the students inside or outside the classroom and provide m-learning features

- Audio/Video elements such as data show, projectors and recording systems

- Classroom Management System; which is highly efficient software that allows a teacher to have full control on the smart classroom components and students' equipment

- Learning Management System (LMS)

- Accessibility and Connectivity

\section{Implementing M-learning in A Smart Classroom: A New Model}

A new model to implement the mobile computing in a contemporary educational environment is presented here. It is illustrated in Figure 1. It should be emphasized here on the smart classroom environment as a controlled one and the learning process is in a closed loop. In other words, the teacher is controlling the learning environment in terms of devices, accessibility and content offering, regardless the mobility of learners. In addition, there is a feedback process going from the system to teacher regarding the students' performance. This feedback can be provided in different formats such as assessment result or activities status. The new model focuses on a controlled learning process in a close loop to ensure that learning is in progress to eliminate the situation that learners are receiving information from instructors without controlling the learning environment and achieving the learning objectives.

Innovative pedagogy in the light of the 21 st century is based on increasing the individualization of teaching and personalization of learning. In other words, to promote the students' brainstorming back and forth until the whole class agrees to a topic they would like to tackle. Smart classrooms embed the ICT completely with mobile features in innovative learning environment to innovate learning and teaching practices in all forms of settings. The learning process, whether formal or non-formal, ensures promoting the investigation, data collection and analysis. It looks at the issues from pedagogical, social, and economic perspectives, formulating strategies and developing innovations for positive change. This will help students come out as a generation fully aware of the powerful relationship between collaborative planning and sustainable change. Accordingly, students will truly understand how sustainability works and how human behavior, and how economic activity and environmental capacity are related [38].

The emotional intelligence is the key factor of the creative learning in smart classrooms. Variety of activities help learners to manage emotions and form positive relationships. It also enables the use of learning resources which foster learners' emotion- 
al knowledge skills (e.g. self-awareness, empathy for others, etc.) [39]. Furthermore, instructors should encourage learners to develop their talents and creative potentials to the fullest in all possible areas [40]. ICT applications with mobile functionality and capabilities offer unprecedented opportunities for exploratory learning and creativity. On the other hand, instructors should build learners' strength, potentials and preferences (i.e. understanding their backgrounds, interests and skills) as crucial resources and drivers of motivation for learning. The anatomy of this model explained as follow:

\subsection{Alignment with the National e-learning Strategy.}

The proposed model emphasized on the alignment between m-learning model in a smart classroom and the integrated e-learning environment with the national educational strategy. This alignment is important to achieve the vision of the educational institution or the educational vision of the country.

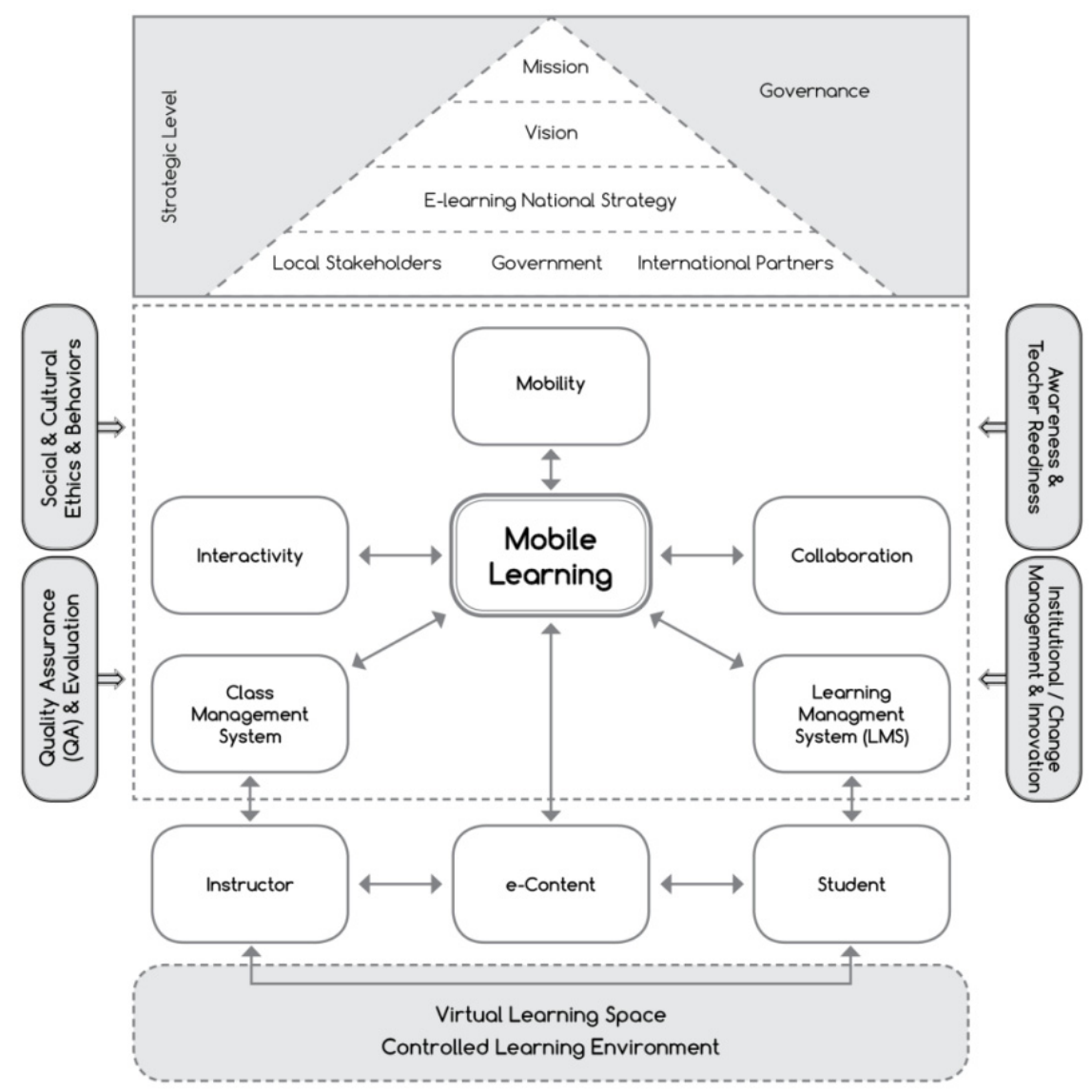

Fig. 1. The New M-Learning Model 


\subsection{Mobile Learning components}

The opportunity to use mobile devices, such as PDAs, tablets, smart phones, wearable devices, ultra-mobile PCs, personal navigation devices, handheld game consoles as learning tools, inside and outside smart classrooms enables innovation and supports students, teachers and stakeholders. There are essential features and infrastructures necessary to support and provide such opportunity. We list below 6 general components which contribute to achieve a successful mobile learning implementation.

Connectivity: Internet has been drastically evolved from just a 'network of computer networks' to a network that seamlessly connects all kinds of digital devices. These connected things are also called 'smart digital objects' with different levels of collaboration. The Internet enables anyone to the connectivity with anything in any place and at any time. Such rapid development of Internet and communication had a direct impact on the educational technologies and the smart classrooms concept $[41$, $6]$.

Interactive Content: The content is fully interactive that allows students to learn at their own pace, in a group or individual basis benefiting of the assessment tools and feedback $[41,7,30]$.

Class Management System: which is highly efficient software and hardware that allow the instructor to have full control of the smart classroom components such as interactive white board, Audio/video elements, data show, projectors, recording systems, lighting, and students' mobile devices [14, 42].

Mobility: mobile learning is characterized by physical mobility in its flexibility of time, pace, and space. The mobility here is the mobility of learners, instructors, and mobility of content $[6,8]$.

Collaboration: collaboration expands the learning opportunities and provides flexible learning environment; anytime anywhere, allowing new modes of teaching and encouraging students' active participation and collaboration within learning space or through online social networks [7,8].

Learning Management System: the mobile LMS improves the course delivery and efficiency. Instructors can send messages, reminders, homework and some other supporting materials to students in mobile platforms. Also, feedbacks on homework and quizzes make the evaluation easier $[43,14]$. This will help to close the loop in the virtual learning space.

\subsection{Change Management -Innovation}

In order to change process to succeed, the principles of change management should be applied properly, starting with extensive and in anticipation planning. The goal of change management is to change the attitudes and behaviors in the educational sector at different levels that includes different organizational and individual layers. Such a change is usually hard. Adopting a new m-learning strategy is also a major change and unsurprisingly, people will resist it. Therefore, using the change management techniques with innovation will support the transition towards the new era with confidence. 


\subsection{Quality Assurance and Evaluation}

m-learning adds complexity to the evaluation process and forces educational institutions to consider m-learning technical features, social norms, and pedagogical issues including learning strategies, learners access, informality, engagement, and ubiquity. Quality Assurance (QA) and control is a great challenge. A clear QA of online content as well as teaching in smart classroom environment is strongly required.

\subsection{Social, Cultural and Ethical issues}

Social and cultural issues have direct impact on instructor's personality in mlearning environment as well as management and society at large. Instructor should achieve his/her pedagogical goals and objectives by understanding learners' needs, behaviors and abilities. These are important and can enforce ethical use of the social networking tools between learners and encouraging the interaction between learners and colleagues in scientific competition atmosphere, respecting intellectual property rights. These also raise the awareness about technology and Internet safe use.

\subsection{Awareness \& Teacher Readiness}

Awareness programs have a vital role in m-learning projects to the fact that these projects target different levels in the society and deal with behavior change. Teacher expertise in these technologies is a challenge to effective integration of mobile learning. Lack of teacher support affects the widespread adoption of mobile learning [4, 24].

\subsection{Virtual Learning Space- Controlled Learning Environment (Closed Loop)}

The virtual learning space created by the new m-learning model that provides a new environment, based on different levels of interactivity. The model exactly means more benefits to instructors as well as students as they will have the educational technology, the teaching/learning practice and the active learning. This will help the instructor in using the LMS or tools of SOL to control the learning process. When conducting a course in a formal educational setting, we believe it is essential for the instructor to have control over various learning activities, such as course announcements, assignments, assessment, and feedback to achieve a collaborative, interactive and innovative learning environment, and then course educational objectives.

\section{M-Learning Challenges in the Context of the New M- Learning Model}

Implementing an efficient M-learning project within the educational environment is still a challenge to most of the educators due to the complex environment that incorporates management, pedagogical, and technological elements. Even though m- 
learning offers many important benefits, still there are number of crucial issues pertained to use mobile technology in education. Some of the challenges imposed by implementing the proposed new m-learning model are addressed in the following paragraphs:

Despite the current interest in the m-learning, there are institutional challenges. The educational institutions need to define a clear policy, device availability, and technical and pedagogical support in order to go for wide-scale implementation of m-learning. The lack of support and institutional policies were cited as institutional obstacles [44, 45]. Also, the change management in most organizations is a critical challenge. One of the most crucial challenges facing the educational institutions is fostering an $\mathrm{m}$ learning project, managing the change within the institution, since it affects all the processes, activities and components. It also affects the people involved in the project such as: managers, administrators, content designers, course developers, decision makers, employees, students and instructors within the educational institution. For the change in process to succeed, the principles of change management must be thoroughly applied properly [46]. It is important for educational institutions to manage such a change with innovation, defining new policies, and creating awareness among all involved in the upcoming m-learning implementation.

Messinger (2012) argued that teachers' resistance to technology innovations in education limits the adoption of m-learning [47]. That was due to instructors' lack of technical knowledge as well as lack of funds for professional development programs [48]. It is important to the institution to create Awareness and Teacher Readiness Program. Also, Media Awareness Campaign (MAC) is a crucial factor of any project to achieve success.

Regarding m-learning applications' design and development, it is challenging to design electronic educational content and to develop m-learning applications that truly support teaching and learning practices. Buff (2013) stated that designing mobile devices requires analysis and assumes knowledge of target audience from one hand and the mobile device in which content going to be developed on the other hand. He stressed on the design considerations and the decisions in the analysis process to achieve m-learning effective solution [49]. The mobile device is more than just a phone; it is equipped with various capabilities and features that can be used to enhance teaching and learning. These capabilities are and not limited to (camera, calculator, readers, geo-location, capture, recording, document review, sensors, internet, search, media player, notifications, calendar, cloud storage, touch screen, messaging, etc.). Understanding the capabilities of a mobile device will help designers and developers to explore the potentials of m-learning. However, there are some technical concerns related to the device itself, which must be considered when designing and developing m-learning applications. Park (2011) listed some technical limitations related to the physical attributes of mobile devices such as: "small screen size; insufficient memory; limited battery; network reliability; excessive screen brightness outside; limitation of software applications; safety and privacy" [25].

As educators are concerned of the integration of technology with various educational activities, serious considerations must be taken when designing the m-learning applications. In order to overcome these challenges, designers and developers must 
understand the three types of design those are: the instructional design, which is an educational design for application; the interface design, which makes the user interface transparent (facilitative) and the graphic and screen design, which is the design of the visual display. The more emphasis the developer puts on these designs, the more useful and functional the application will be [50].

The introduction of a new technology into existing social environments having their patterns of interaction and culture must be considered. These new technological tools should be used accordingly, but they can also have a major impact transforming those cultures and practices. Mobile technologies and applications challenge traditional distinctions between the new m-learning environments and the traditional classroom learning, which generates new learning and teaching opportunities. The introduction of mobile technology and its features to education has some social, cultural and behavioral implications. Naismith et al. (2004) stressed that the informality of mlearning represents a challenge for the traditional educational settings [31]. They believed that informality makes learning more casual in nature, which clashes with classroom setting and hence affect its educational gains. Kadirire, (2009) also found a drawback to mobile learning because students get distracted with their personal things on their mobiles, which makes mobile learning activities subject to frequent interruptions [32].

Al-Sharhan (2016) discussed the behavioral and social competencies, knowledge and the cultural competencies. He stated that instructors' role in e-learning environment is to facilitate the learning process, and he/she should play multiple roles when interacting with learners to promote positive behaviors. He/she should possess certain behavioral and social competencies [36]. Furthermore, the cultural considerations increase the complexity of designing the learning interfaces due to more variables to be added. Introducing learning applications to new culture brings many issues that need to be investigated. Firstly, it is very important to understand the nature of the target students' culture and to use the findings as a basis for the design of the application [50]. The accessibility of the mobile devices is another challenge. For successful implementation of m-learning, students and teachers must have an access to mobile devices [51].

Evaluating m-learning projects forms a real challenge. The evaluation is a central activity in the lifecycle of the interactive systems design and m-learning adds additional challenges against the evaluation of both of technology and learning outcome [52]. The evaluation takes place during the application's production and after the delivery. The development of evaluation strategies of education focused on the faceto-face contact with learners in classrooms. Now, m-learning, adds complexity to the evaluation process and forces the educational institutions to consider m-learning technical features, social norms, and pedagogical theories including learning strategies, learning outcome, engagement, collaboration and ubiquity.

Regarding the evaluation of m-learning, Messinger (2012) stated that there was a lack of evidence regarding effective use of mobile technologies in the classroom [47]. He believes that this will limit the widespread adoption of mobile learning. He emphasizes on looking at various methods to evaluate the effectiveness and asks how to assess learning outcome. Kukulska-Hulme and Traxler (2005) urged the educators, 
the researchers, and the policy makers to integrate evaluation and quality assurance strategies into the development and the implementations of m-learning technologies. They demonstrated that the design, the planning, the implementation and the evaluation of mobile technologies use must be integrated in order to be successful [53].

\section{$7 \quad$ Case Study}

The proposed integrated m-learning model has been utilized to implement the national e-learning strategy in the Ministry of Education (MOE) of Kuwait. In Kuwait, there are 850 public schools spread across six Educational districts. The MOE caters to around 500,000+ students spread across Kindergarten, Primary, Intermediate and Secondary schools [54]. The following Table 1 depicts the situation at MOE Kuwait.

The MOE has launched a national e-learning project in Kuwait based on Kuwait elearning strategy that was developed in 2008. The implementation plan of e-learning project was divided into three phases as follows:

- Phase- I: High schools (Year 10-12)

- Phase -II: Intermediate schools (Year 6-9)

- Phase- III: Primary schools (Year 1-5)

Table 1. Public Schools in Kuwait- From Central Statistical Bureau [54]

\begin{tabular}{|c|c|c|c|c|c|c|c|c|}
\hline \multirow{2}{*}{ Stage } & \multicolumn{2}{|c|}{ Schools } & \multicolumn{2}{|c|}{ Classrooms } & \multicolumn{2}{|c|}{ Teachers } & \multicolumn{2}{|c|}{ Students } \\
\hline & $M$ & $F$ & $M$ & $F$ & $M$ & $F$ & $M$ & $F$ \\
\hline \multirow{2}{*}{$\begin{array}{l}\text { Kindergarten } \\
K G 1-K G 2\end{array}$} & \multirow{2}{*}{\multicolumn{2}{|c|}{199}} & \multirow{2}{*}{\multicolumn{2}{|c|}{1,807}} & 0 & 6,33 & 20,93 & 22,19 \\
\hline & & & & & & 332 & \multicolumn{2}{|c|}{43,120} \\
\hline \multirow{2}{*}{$\begin{array}{l}\text { Primary } \\
\text { Education } \\
\text { Year } 1 \text { - } 5\end{array}$} & 133 & 126 & 2,91 & 3,03 & 1,37 & 21,38 & 68,85 & 74,93 \\
\hline & \multicolumn{2}{|c|}{259} & \multicolumn{2}{|c|}{5,941} & \multicolumn{2}{|c|}{22,742} & \multicolumn{2}{|c|}{143,773} \\
\hline \multirow{2}{*}{$\begin{array}{l}\text { Intermediate } \\
\text { Education } \\
\text { Year } 6-9\end{array}$} & 100 & 106 & 2,17 & 2,29 & 8,33 & 10,22 & 51,42 & 55,24 \\
\hline & \multicolumn{2}{|c|}{206} & \multicolumn{2}{|c|}{4460} & \multicolumn{2}{|c|}{18,554} & \multicolumn{2}{|c|}{106,663} \\
\hline \multirow{2}{*}{$\begin{array}{l}\text { Secondary } \\
\text { Education } \\
\text { Year } 10-12\end{array}$} & 65 & 74 & 1,31 & 1,66 & 5,86 & 7,42 & 28,71 & 38,58 \\
\hline & \multicolumn{2}{|c|}{139} & \multicolumn{2}{|c|}{2,966} & \multicolumn{2}{|c|}{13,274} & \multicolumn{2}{|c|}{67,289} \\
\hline
\end{tabular}

Phase-I have been launched in 2010 and cater for 80,500 students and teachers. In this phase the infrastructure project, the learning gateway portal and LMS, the smart classrooms and schools ( $\sim 500$ classrooms), the teacher readiness and awareness projects are completed and implemented to serve students of age from 9 to 12 and 139 secondary schools spread across the six Educational Districts. 
The proposed model for m-learning has been implemented in phase-I of the elearning project in Kuwait. The MOE distributed 80,500 one to one mobile devices (Tablets) on students and teachers in the academic year 2015-2016. Currently, the teacher readiness program is executed to prepare the teacher for the new era. This program is designed by the e-learning team at MOE and international vendors.

\section{Conclusions and Future Work}

This work presented a new comprehensive mobile learning model in the context of smart classrooms environment as a part of a holistic approach to implement an efficient TEL Environment. The presented model is a crucial factor for a successful implementation of m-learning systems against the challenges addressed in this paper. This is because contemporary learning environments are complex, incorporate several systems and require certain expertise and competencies to provide high-quality education. This study also introduced a new m-learning definition which focused on controlling the learning environment. In addition, some of the challenges of implementing m-learning projects were discussed such as institutional design, development, cultural, social, and evaluation of challenges. However, several future directions are required to extend the research work towards a fruitful and efficient m-leaning system. These directions can be categorized into two main areas. The first direction is studying m-learning design in terms of the content, its usability, interactivity and the evaluation process of that content. The second direction is designing an efficient change behavior model and measuring its impact on the learning process.

\section{$9 \quad$ References}

[1] R. Arora and I. Chhabra, "Extracting components and factors for quality evaluation of elearning applications," in Engineering and computational sciences (raecs), Chandigarh , 2014. https://doi.org/10.1109/raecs.2014.6799553

[2] M. A. Lubis, S. R. Ariffin, T. A. Muhamad, M. S. Ibrahim and I. S. Wekke, "The integration of ICT in the teaching and learning processes: A study on smart school of malaysia," in 5th wseas/iasme international conference on education technology, 2009.

[3] S. AL-Sharhan, A. Al-Hunaiyyan and W. Gueaieb, "Success Factors for an Efficient Blended e-learning," in Internet and Multimedia Systems and Applications (IMSA), Honolulu, Hawaii, USA, 2006.

[4] S. Al-Sharhan and A. Al-Hunaiyyan, "Towards an effective integrated e-learning system: Implementation, quality assurance and competency models. In Digital information management (icdim)," in Seventh International Conference, Macau, 2012.

[5] H. Seyed Ebrahim, K. Ezzadeen and A. K. Alhazmi, "Acquiring Knowledge through Mobile Applications," International Journal of Interactive Mobile Technologies (iJIM), vol. 9, no. 3, 2014.

[6] P. Berking, M. Birtwhistle, S. Gallagher and J. Haag, "Mobile Learning Survey Report," Advanced Distributed Learning Initiative, 2013. 
Paper-A New Mobile Learning Model in the Context of Smart Classroom Environment: A Holistic...

[7] J. Cheon, S. Lee, S. M. Crooks and J. Song, "An investigation of mobile learning readiness in higher education based on the theory of planned behavior," Computers \& Education, vol. 59, no. 3, p. 1054-1064, 2012. https://doi.org/10.1016/j.compedu.2012.04.015

[8] M. Sharples, "Big issues in Mobile Learning," University of Nottingham, UK, 2006.

[9] A. K. Alhazmi, A. A. Rahman and H. Zafar, "Conceptual model for the academic use of Social Networking Sites from student engagement perspective," in 2014 IEEE Conference on e-Learning, e-Management and e-Services (IC3e 2014), Melbourne, Australia 10-12 December 2014, 2014. https://doi.org/10.1109/ic3e.2014.7081232

[10] H. Beetham and R. Sharpe, Rethinking pedagogy for a digital age: Designing for $21 \mathrm{st}$ century learning, 2 ed., London: routledge, 2013.

[11] P. Kim, E. Buckner, H. Kim, T. Makany and N. Teleja, "A comparative analysis of a game-based mobile learning model in low socioeconomic communities of India," International Journal of Educational Development, vol. 32, no. 2, pp. 329-340, 2012. https://doi.org/10.1016/j.ijedudev.2011.05.008

[12] J. Traxler, "Mobile learning in international development," in Global mobile learning implementations and trends, A. Tsinakos and M. Ally, Eds., Beijin, China Central Radio \& TV University Press, 2013, pp. 45-60.

[13] S. Al-Sharhan and A. Al-Hunaiyyan, "A new efficient blended e-learning model and framework for K12 and higher education: Design and implementation success factors. In The Fifth International Conference on Digital Information Management (ICDIM)," Canada, 2010.

[14] S. Al-Sharhan, T. Al-Sedrawi and H. Al-Sharrah, E-learning Strategies, and implementation Projects, Ministry of Education, 1 ed., Kuwait: Ministry of Education, 2010.

[15] Gartner, "Gartner says worldwide traditional PC, tablet, ultramobile and mobile phone shipments to grow 4.2 percent in 2014," 77 2014. [Online]. Available: http://www.gartner.com/newsroom/id/2791017. [Accessed 207 2016].

[16] Y. Hsu and Y. Ching, "Mobile app design for teaching and learning: Educators' experiences in an online graduate course," The International Review of Research in Open and Distance Learning, vol. 14, no. 4, pp. 117-139, 2013. https://doi.org/10.19173/ irrodl.v14i4.1542

[17] C. Looi and Y. Toh, "Orchestrating the flexible mobile learning classroom," in Increasing access through mobile learning (pp.161-174). , Canada:, M. Ally and A. Tsinakos , Eds., Vancouver, Commonwealth of Learning and Athabasca University, 2014, pp. 161-174.

[18] Y. Hsu and Y. Ching, "Research priorities in mobile learning: An international Delphi study," Canadian Journal of Learning and Technology, vol. 40, no. 2, pp. 1-22, 2014.

[19] Y. Hsu and Y. Ching, "A Review of Models and Frameworks for Designing Mobile Learning Experiences and Environments," The Canadian Journal of Learning \& Technology. published by Canadian Center of Science and Education, vol. 41, no. 3, pp. 1$22,2015$.

[20] M. Alrasheedi, A Maturity Model for Mobile Learning. Ph.D. Thesis., Ontario: The University of Western Ontario, 2015.

[21] M. Sarrab, Y. Baghdadi, H. Shihi and H. Bourdoucen, "A model for mobile learning nonfunctional requirement elicitation.," International Journal of Mobile Learning and Organisation, vol. 10, no. 3, pp. 129-158, 2016. https://doi.org/10.1504/IJMLO. 2016.077862

[22] G. Vavoula and M. sharples, "Meeting the challenges in evaluating mobile learning: A 3level evaluation framework," International Journal of Mobile and Blended Learning, vol. 1, no. 2, pp. 54-75, 2009. https://doi.org/10.4018/jmbl.2009040104 
[23] M. Koole, "A Model for Framing Mobile Learning," in Mobile Learning: Transforming the Delivery of Education and Training, M. Ally, Ed., Edmonton, Athabasca University Press, 2009, pp. 25-47.

[24] H. Peng, Y. Sue, C. Chou and C. Tsai, "Ubiquitous knowledge construction: Mobile learning re-defined and a conceptual framework," Peng, H., Su, Y., Chou, C., \& Tsai, C. Innovations in Education and Teaching International, 46(2), 171-183, vol. 46, no. 2, pp. 171-183, 2009.

[25] Y. Park, "A Pedagogical Framework for Mobile Learning: Categorizing Educational Applications of Mobile Technologies into Four Types," International Review, vol. 12, no. 2, 2011. https://doi.org/10.19173/irrodl.v12i2.791

[26] J. Huang, Y. Lin and S. Chuang, "Elucidating user behavior of mobile learning: A perspective of the extended technology acceptance model," The Electronic Library, vol. 25, no. 5, pp. 585-598, 2007. https://doi.org/10.1108/02640470710829569

[27] S. Park, M. Nam and S. Cha, "University students' behavioral intention to use mobile learning: Evaluating the technology acceptance model," British Journal of Educational Technology, vol. 43, no. 4, pp. 592-605, 2012. https://doi.org/10.1111/j.14678535.2011.01229.x

[28] J. Traxler, "Defining, discussing and evaluating mobile learning: The moving finger writes and having writ....," The International Review of Research in Open and Distance Learning, vol. 8, no. 2, pp. 9-24, 2007. https://doi.org/10.19173/irrodl.v8i2.346

[29] S. Kinash, J. Brand and T. Mathie, "Challenging mobile learning discourse through research: Students perceptions of Blackboard Mobile Learn and iPads," Australian Journal of Educational Technology, vol. 28, no. 4, pp. 639-655, 2012. https://doi.org/10.14742/ ajet.832

[30] C. P. Newhouse, P. J. Williams and J. Pearson, "Supporting mobile education for preservice teachers," Australasian Journal of Educational Technology, vol. 22, no. 3, p. 289311, 2006. https://doi.org/10.14742/ajet.1288

[31] L. Naismith, P. Lonsdale, G. Vavoula and M. Sharples, "Literature Review in Mobile Technologies and Learning," Futurelab Series Report 11, 2004.

[32] J. Kadirire, "Mobile learning demystified," in The evolution of mobile teaching and learning, California, Informing Science Press, 2009, pp. 15-56.

[33] E. Dahlstrom and J. Bichsel, "ECAR Study of Undergraduate Students and Information Technology," ECAR, Louisville, CO, 2014.

[34] V. Tomberg, M. Laanpere, T. Ley and P. Normak, "Sustaining Teacher Control in a BlogBased Personal Learning Environment," International Review of Research in Open and Distance Learning, vol. 14, no. 3, pp. 109-133, 2013. https://doi.org/10.19173/irrodl. v14i3.1397

[35] W. Xie, Y. Shi, G. Xu and D. Xie, "Smart classroom-an intelligent environment for teleeducation," in In Advances in multimedia information processingpcm, Springer, 2001, p. 662-668. https://doi.org/10.1007/3-540-45453-5 85

[36] S. Al-Sharhan, "Smart classrooms in the context of technology-enhanced learning (TEL) environment: A holistic Approach," in Transforming Education in the Gulf Region Emerging Learning technologies and Innovative Pedagogy for the 21st Century, London, Taylor \& Francis, 2016.

[37] G. Bautista and F. Borges, "Smart classrooms: Innovation in formal learning spaces to transform learning experiences," Bulletin of the IEEE Technical Committee on Learning Technology, vol. 15, no. 3, p. 18-21, 2013. 
[38] S. Bocconi, P. Kampylis and Y. Punie, "Innovating teaching and learning practices: Key elements for developing creative classrooms in europe," Joint Research Center, Spain, 2012.

[39] C. E. Domitrovich, R. C. Cortes and M. T. Greenberg, "Improving young childrens social and emotional competence: A randomized trial of the preschool paths curriculum," The Journal of Primary Prevention, vol. 28, no. 2, p. 67-91, 2007. https://doi.org/10.1007/ s10935-007-0081-0

[40] J. C. Kaufman, R. A. Beghetto, J. Baer and Z. Ivcev, "Creativity polymathy: What benjamin franklin can teach your kindergartener," Learning and Individual Differences, vol. 20, no. 4, p. 380-387, 2010. https://doi.org/10.1016/j.lindif.2009.10.001

[41] A. K. Alhazmi and A. A. Rahman, "Facebook in Higher Education: Students' Use and Perceptions," AISS: Advances in Information Sciences and Service Sciences, vol. 5, pp. 32 - 41, 2013.

[42] C. Bolick and J. Cooper, "Classroom management and technology," in Handbook of classroom management. Research, practice, and contemporary issues, C. Everston and C. Weinstein, Eds., New York, Lawrence Erlbaum Associates., 2006, pp. 541-558.

[43] A. Alhazmi and A. Rahman, "Why LMS failed to support student learning in higher education institutions. e-Learning, E-Management and E-Services (IS3e), 2012 IEEE Symposium," Kuala Lumpur, 2012.

[44] I. Ismail, S. N. Azizan and N. Azman, "Mobile phone as pedagogical tools: Are teachers ready," International Education Studies, vol. 6, no. 3, p. 36-47, 2013. https://doi.org/10.5539/ies.v6n3p36

[45] Y. Tai and Y. L. Ting, "Adoption of mobile technology for language learning: Teacher attitudes and challenges," The JALT CALL Journal, vol. 7, no. 1, pp. 3-18, 2011.

[46] L. Dublin, Marketing and change management for e-learning: Strategies for engaging learning, motivating managers and energizing organizations, In W.Brandon (Ed.)strategy, Handbook of e-learning (PP. 45-49). Santa Rosa: The eLearning Guild, 2007.

[47] J. Messinger, "M-learning| An exploration of the attitudes and perceptions of high school students versus teachers regarding the current and future use of mobile devices for learning," 2012. [Online]. Available: http://gradworks.umi.com/3487951.pdf.

[48] D. Herro, D. Kiger and C. Owens, "Mobile technology: Case-based suggestions for classroom integration and teacher educators," Journal of Digital Learning in Teacher Education, vol. 30, no. 1, pp. 30-40, 2013. https://doi.org/10.1080/21532974.2013. 10784723

[49] T. Buff, "Top 5 Design Considerations for Creating Mobile Learning," 2013. [Online]. Available: http://elearningindustry.com/top-5-design-considerations-for-creating-mobilelearning.

[50] A. Al-Hunaiyyan, Design of Multimedia Software in Relation to Users' Culture. Ph.D thesis, University of Hertfordshire, UK, 2000.

[51] A. Cushing, "A case study of mobile learning in teacher training-Mentor ME (Mobile enhanced mentoring)," vol. 19, pp. 1-4, 2011.

[52] H. Al-Hajraf and S. Al-Sharhan, "Total quality management (TQM) of blended e-learning systems: A new integrated model and framework," The Literacy Information and Computer Education Journal (LICEJ), vol. 3, no. 1, p. 591-598, 2012. https://doi.org/10.20533/licej.2040.2589.2012.0080

[53] A. Kukulska-Hulme and J. Traxler, Mobile learning: A handbook for educators and trainers, London: Routledge, 2005.

[54] C. S. B. CSB, KUWAIT: The Higher Council of Planning \& Development, 2015. 


\section{Authors}

Ahmed Al-Hunaiyyan is a faculty member of the department of Computer and Information systems at PAAET, Kuwait. He earned his PhD. Degree in the field of Computer Science, specializing in Multimedia interface design, from Hertfordshire University, UK

Salah Al-Sharhan is Associate Professor, Computer Science Department (2002now). He is also the Vice President for Academic Affairs at 'Gulf University for Science and Technology (GUST), Kuwait. He earned his Ph.D. in Systems Design Engineering with an emphasis on Computational Intelligence from 'Waterloo University' in 2002.

Rana Alhajri is a faculty member in the department of Computer Science at the Higher Institute at (PAAET) in Kuwait. She earned her PhD. Degree in the field of Computer Science, from Brunel University, UK. Her research interest is Hypermedia and Multimedia design, HCI, Usability, and social media.

Article submitted 30 August 2016. Published as resubmitted by the authors 11 November 2016. 